\title{
Assessing the effects of load models on MV network losses
}

Link to publication record in Manchester Research Explorer

\section{Citation for published version (APA):}

Ballanti, A., \& Ochoa, L. F. (2015). Assessing the effects of load models on MV network losses. In Australasian Universities Power Engineering Conference AUPEC 2015 (pp. 1-6)

\section{Published in:}

Australasian Universities Power Engineering Conference AUPEC 2015

\section{Citing this paper}

Please note that where the full-text provided on Manchester Research Explorer is the Author Accepted Manuscript or Proof version this may differ from the final Published version. If citing, it is advised that you check and use the publisher's definitive version.

\section{General rights}

Copyright and moral rights for the publications made accessible in the Research Explorer are retained by the authors and/or other copyright owners and it is a condition of accessing publications that users recognise and abide by the legal requirements associated with these rights.

\section{Takedown policy}

If you believe that this document breaches copyright please refer to the University of Manchester's Takedown Procedures [http://man.ac.uk/04Y6Bo] or contact uml.scholarlycommunications@manchester.ac.uk providing relevant details, so we can investigate your claim.

\section{OPEN ACCESS}




\section{Assessing the Effects of Load Models on MV Network Losses}

\author{
Andrea Ballanti \\ School of Electrical and Electronic Engineering \\ The University of Manchester \\ Manchester, UK \\ andrea.ballanti@postrgrad.manchester.ac.uk
}

\author{
Luis F. Ochoa \\ School of Electrical and Electronic Engineering \\ The University of Manchester \\ Manchester, UK \\ luis_ochoa@ieee.org
}

\begin{abstract}
Network losses are often a key metric in evaluating the performance of planning and/or operational strategies. However, their assessment is traditionally carried out assuming a constant power load model that does not reflect the actual voltage-demand dependency, thus leading to inaccurate results. This work quantifies, in a real UK medium voltage (MV) network, the impact of three classic load models (constant power, current and impedance) on the quantification of energy and power network losses. A time-varying ZIP model designed for the UK residential demand is used as benchmark. Results indicate that the constant power load model, although underestimates the network losses throughout the year, outperforms the other models during summer (maximum error of $3 \%$ on power and $1.5 \%$ in energy). However, during winter the constant current model showed the best performance. The constant impedance model led to the highest errors and, consequently, should be in general avoided.
\end{abstract}

Index Terms-Distribution networks, energy losses, load models, medium voltage, power losses, time-series.

\section{INTRODUCTION}

Network losses are one of the key variables in evaluating the benefits of planning and/or operational strategies. For instance, in [1] a multi-period optimal power flow is adapted to quantify the optimal sizes of Distributed Generator units (DGs) that minimize power and network losses. In [2] a control logic of plug-in electric vehicle is proposed in order to minimize the impact on the network losses. The impact of different type of DGs on network losses is the main objective in [3].

In addition, Distribution Network Operators (DNOs) around the world are keen in accurately quantifying (and then reducing) power and energy losses in their networks. Indeed, in several countries, such as the UK, the electricity regulator sets loss targets that in turn become financial rewards or penalties for DNOs. Moreover, a proper evaluation of network losses (also known as technical losses) allows detecting fraud activities undertaken by consumers (non-technical losses) that, especially for developing countries, may have a significant impact on the national economy [4].
Traditionally, technical losses are quantified assuming that the drawn demand is independent from the supplied voltage. However, since the ' 70 s, field measurements have highlighted a different relationship between voltage and demand (i.e., load models) [5, 6]. Consequently, given the key role that network losses play in a variety of planning and operational strategies, it is important to assess the impact that an inaccurate load model might have on their quantification.

Nevertheless this impact was investigated in [7] only a single load levels a simplifed MV network was considered. In addition, no impact in terms of energy was investigated. In [8] the impact of different load models on size and location of DG was assessed. However, the adoption of a syntehtic network and the use of a load model that neglects the time-varying changes in load composition (i.e., static) $[6,9]$ limits the confidence on the final outcomes.

This work evaluates the impact that the three classic load models, i.e., constant power, constant current and constant impedance, have on the quantification of energy and power losses on a real UK MV network. A 10-min time-series analysis during winter and summer days is undertaken. A time-varying ZIP model [9], specifically designed for the UK residential sector, is adopted as benchmark to evaluate the performance of the three classic load models.

The rest of the paper is structured as follows. Section II describes the MV UK network and load models adopted for the study. In section III the procedure to generate load profile and models per secondary substation is illustrated. The results of the impact assessment are shown and discussed in section IV. Finally, conclusions are drawn in section V.

\section{NETWORK AND LOAD MODELS}

This section presents the main features of the MV network, residential load models and profiles adopted in this work.

\section{A. UKMV Network}

A real UK MV distribution network $(11 \mathrm{kV})$ from the North West of England is used as test case. It has been fully modelled from GIS-based data into OpenDSS [10] 


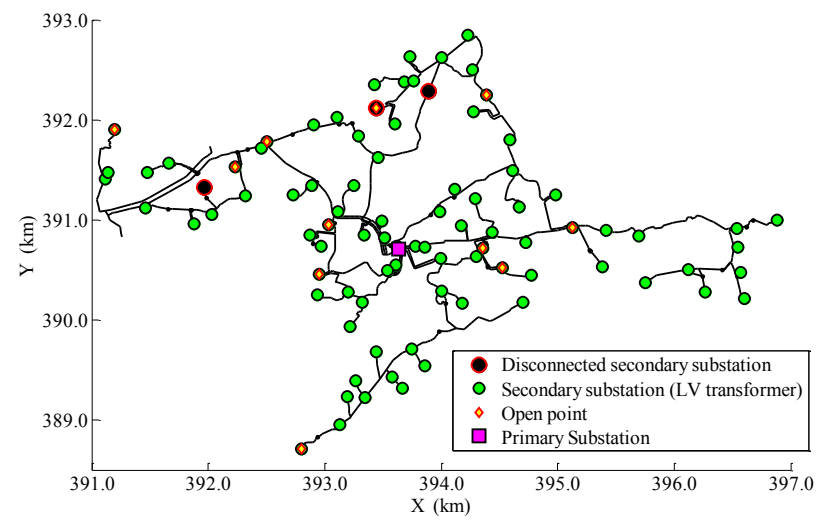

Fig.1 Topology of the analyzed real UK MV network

TABLE I PARAMETERS OF THE MOST COMMON CABLES ADOPTED IN THE ANALYZED MV NETWORK

\begin{tabular}{cccc}
\hline \hline $\begin{array}{c}\text { Cross Section } \\
\left(\mathbf{i n}^{2}-\mathbf{m m}^{2}\right)\end{array}$ & $\begin{array}{c}\mathbf{R} \\
(\mathbf{\Omega} / \mathbf{k m})\end{array}$ & $\begin{array}{c}\mathbf{X} \\
(\mathbf{\Omega} / \mathbf{k m})\end{array}$ & $\begin{array}{c}\text { \% of the total } \\
\text { cable length }\end{array}$ \\
\hline $0.06-39$ & 0.463 & 0.095 & $9.1 \%$ \\
$0.1-65$ & 0.275 & 0.095 & $16.7 \%$ \\
$0.15-96$ & 0.188 & 0.083 & $18 \%$ \\
$0.2-129$ & 0.142 & 0.083 & $15.9 \%$ \\
$0.25-162$ & 0.113 & 0.079 & $11 \%$ \\
\hline \hline in $^{2}=$ Inch squared & &
\end{tabular}

TABLE II PARAMETERS OF THE MOST COMMON LV TRANSFORMERS ADOPTED IN THE ANALYZED MV NETWORK

\begin{tabular}{cccc}
\hline \hline $\begin{array}{c}\text { Transformer } \\
\text { type }\end{array}$ & $\begin{array}{c}\text { Nominal } \\
\text { Rating } \\
\text { (kVA) }\end{array}$ & $\begin{array}{c}\mathbf{R} \\
\text { (p.u. } \\
\text { of rating) }\end{array}$ & $\begin{array}{c}\mathbf{X} \\
\text { (p.u. } \\
\text { of rating) }\end{array}$ \\
\hline Ground mounted & $750-500$ & 0.0125 & 0.0462 \\
Pole mounted & 50 & 0.0234 & 0.0385 \\
\hline \hline
\end{tabular}

considering real electric parameters for lines and transformer, Table I and Table II, making more close to reality the final network losses quantification.

The system, shown in Fig.1, is supplied by two 14 MVA $33 / 11 \mathrm{kV}$ transformers located at the primary substation. A total of $89 \mathrm{LV}$ transformers $(11 / 0.433 \mathrm{kV})$ are fed by a cumulative line length of around $46 \mathrm{~km}$. More than $95 \%$ of the 11,997 customers are residential, hence the industrial and commercial components are neglected.

The yearly demand in the analyzed MV network varies between $3.5 \mathrm{MW}$ during summer night to $15 \mathrm{MW}$ at winter/autumn peak (at around 18:00) as shown in Fig. 2.

\section{B. UK Residential Load Profiles}

To reproduce a realistic time-varying behavior of the residential demand a UK-based tool (CREST tool [11]) is adopted. This tool is able to stochastic reproduce the daily power demand of a single dwelling with 1-min resolution (averaged with 10-min in this work). Seasonality, number of occupants, geographical location, type of day (i.e., weekend or weekday) and data on energy and power consumption for the most common appliances are considered within the tool. To illustrate a few dwelling profiles, examples are provided in Fig. 3.

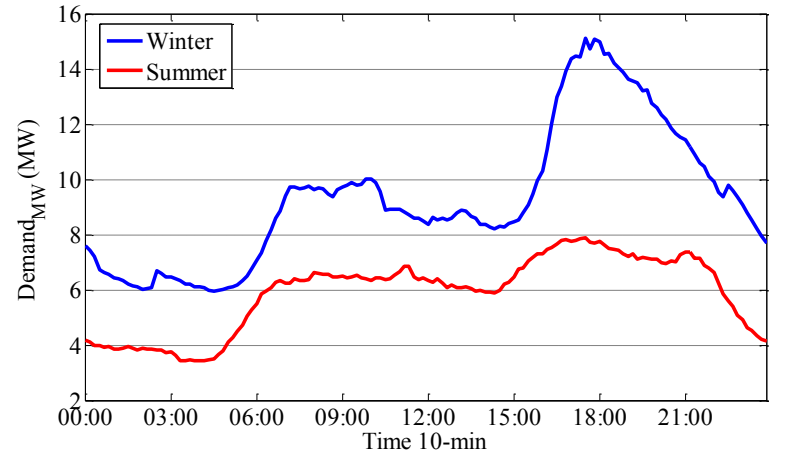

Fig. 2 Monitored demand for the analyzed primary substation in summer

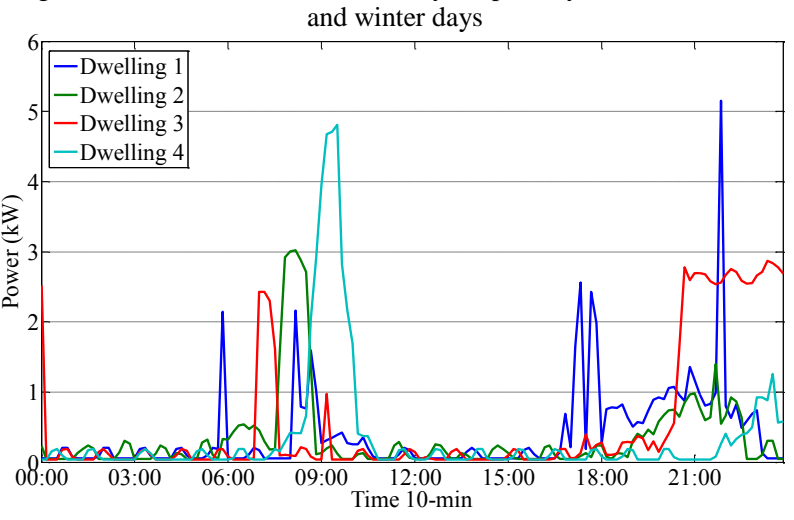

Fig. 3 Examples of winter, weekday UK dwelling profiles produced by CREST tool

\section{Load Models}

A load model is defined as the mathematical relationship between supplied voltage and drawn demand for a specific load. This could be either a single appliance or the aggregated demand at a given point in the network. The models adopted in this paper are described as follows.

\section{1) Classic Load Models}

It is accepted that every load is characterized by its own voltage-demand relationship. In particular, the following classification is widely adopted in the literature:

- Constant power: these loads are defined insensitive to voltage variation. This is the most adopted assumption in power flow studies [12]. However, only Switch Mode Power Supply appliances in reality belong to this category.

- Constant current: A linear relationship between voltage and demand is considered.

- Constant impedance: A quadratic relationship between power and voltage is defined. Resistive loads without thermal control (e.g., space or water heaters) belong to this category [12].

\section{2) UK-based Time-Varying Load Model}

A recent growing of interest in load modelling has highlighted the inaccuracies brought by the previously 
TABLE III EQUIVALENT NP-ZIP FOR THE CLASSIC LOAD MODELS

\begin{tabular}{cc|ccc}
\hline \hline Load Model & $\mathbf{n p}$ & $\mathbf{Z}_{\mathbf{P}}$ & $\mathbf{I}_{\mathbf{P}}$ & $\mathbf{P}_{\mathbf{P}}$ \\
\hline Constant power & 0 & 0 & 0 & 1 \\
Constant current & 1 & 0 & 1 & 0 \\
Constant impedance & 2 & 1 & 0 & 0 \\
\hline \hline
\end{tabular}

$$
\begin{gathered}
P=P_{0}\left(\frac{V}{V_{0}}\right)^{n p} \\
P=P_{0}\left[Z_{P}\left(\frac{V}{V_{0}}\right)^{2}+I_{P} \frac{V}{V_{0}}+P_{P}\right]
\end{gathered}
$$

described approaches [12]. A more sophisticated model called "exponential" is shown in (1) where $P_{0}$ is the power at the reference voltage level. This is usually the nominal voltage $V_{0}$, i.e., $230 \mathrm{~V}$ phase to neutral for the residential customer in the UK. $P$ indicates the power drawn at the generic voltage $V$.

The key element in (1) is the $n p$ coefficient. Whereas $n p$ can adopt any fractional value increasing the flexibility of the model, for the constant power, current and impedance load model the $n p$ can only be 0,1 or 2 respectively.

However, an even more accurate model called polynomial (or ZIP), shown in (2) is used in the literature and preferred to the exponential [13] when possible. It is of interest to remark that the three classic load models can be described by both the $n p$ (1) and ZIP (2) coefficients as shown in Table III.

The fourth load model, adopted in this work as a benchmark, is a time-varying (i.e., changes through time) ZIP model designed for the UK residential sector [9]. To develop such model firstly a literature review has been carried out in order to define a ZIP model for each single appliance that could be found in a common UK dwelling [14]. Thereafter, by adopting the CREST tool, the load profiles for each dwelling have been stochastically generated. Finally, the daily ZIP model for each dwelling is calculated by aggregating each single appliance load model and profile [9].

This approach, belonging to the category of componentbased load model, captures the variability in the load composition and consequently the natural variation of the load response to voltage changes [6].

\section{LV TRANSFormer DEMAND MODELLING}

This section describes the procedure to model the aggregated demand per secondary substation in terms of demand profile and aggregated load model. Indeed, as the downstream LV networks have not been explicitly modeled, the LV transformers represent the end point of the analyzed MV network.

The previously defined load profiles and models are adopted in a power flow analysis in order to quantify the

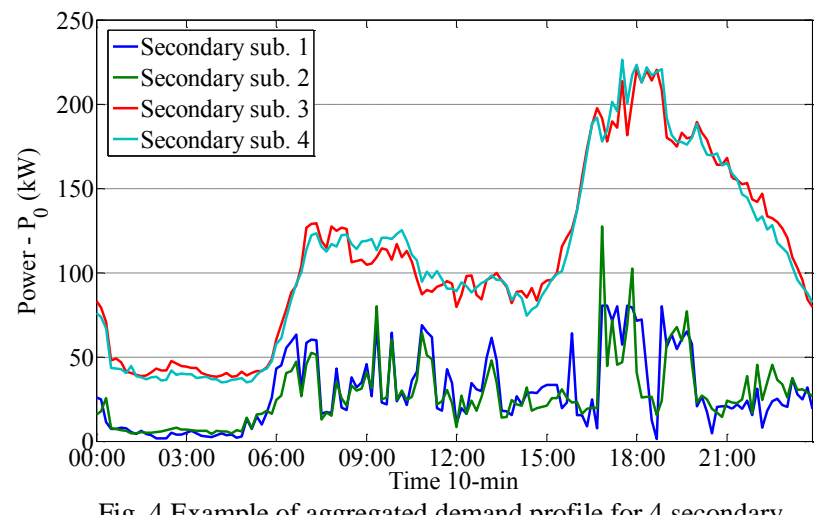

Fig. 4 Example of aggregated demand profile for 4 secondary substations

impact that different load models may have on the quantification of network losses.

\section{1) Demand Profiling}

In order to provide an overview on the impact that different load models may have on the quantification of network losses through the year two different days (winter and summer) are considered. The corresponding monitored demands at the primary substation are shown in Fig. 2.

To produce the aggregated demand profile per secondary substation in those days the CREST tool is adopted by generating a pool of 1,000 domestic load profiles for the North West of England. National statistics data on the number of occupants per dwelling are also considered [15].

Thereafter, for every secondary substation, knowing the number of customers $(\mathrm{N}), \mathrm{N}$ randomly selected load profiles are extracted from the pool and aggregated in order to obtain the total demand in the chosen day.

Finally, the demand profile of every secondary substation is scaled to match the total monitored demand, Fig. 2 in order to make the final figure in terms of the quantification of energy and power losses as realistic as possible.

The demand so obtained for four secondary substations $\left(\mathrm{P}_{0}{ }^{1}\right.$ to $\left.\mathrm{P}_{0}{ }^{4}\right)$ is shown in Fig. 4. The secondary substations 3 and 4 present a higher number of customers that makes theirs aggregated demand profiles higher and "smoother" compared to those in secondary substations 1 and 2 .

\section{2) Load Modelling}

The demand profiles $\left(P_{0}^{i-t h}\right)$ previously generated for every secondary substation are adopted as the common reference power $P_{0}$ for all the load models (in (1) and (2)). Consequently, if the supplied voltage $(V)$ is equal to the nominal $\left(V_{0}\right)$ the drawn demand $(P)$ will be equal to $P_{0}$ and will be the same for all the different load models (as clearly shown in (2)).

This assumption allows comparing the outcomes of the load models as the impact on the network losses is only due to their different parameters (Z-I-P or $n p$ ) shown in Table III. 


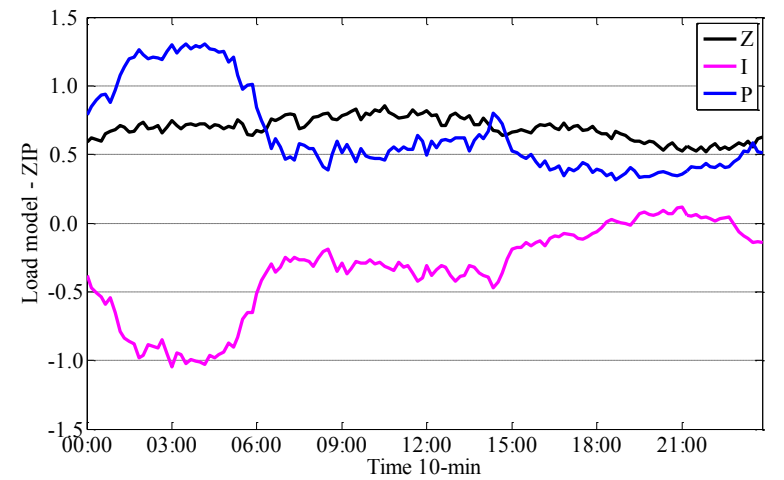

Fig. 5 Time-varying ZIP model parameters for one secondary substation

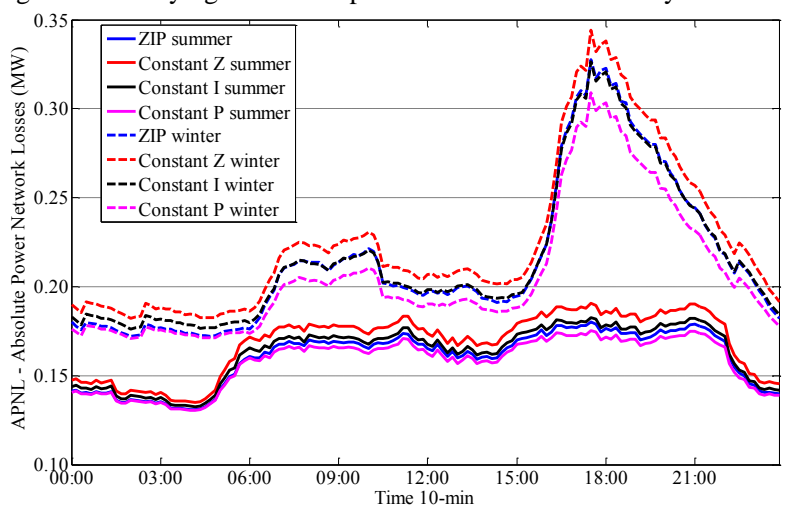

Fig. 6 Absolute network power losses in summer and winter day

It is worth noticing that those parameters are time constant and equal among secondary substations modelled with the classic load models. On the other hand, the time-varying ZIP model describes a more realistic voltage demand relationship considering its time-varying nature and also catering for the possible diversity (due to the randomness on the dwelling profile selection) from one secondary substation to another as discussed in [9]. An example of the obtained time-varying ZIP parameters for one secondary substation is shown in Fig. 5.

\section{RESUlTS AND DISCUSSION}

This section reports and discusses the impacts that the three classic load models have on the network losses quantification. For this purpose, a power flow analysis using OpenDSS [10] is carried out for the considered summer and winter days.

Fig. 6 shows the absolute power network losses $(A P N L)$. In particular, the higher demand levels in winter (around $40 \%$ more at peak hours compared to summer, Fig. 2) justifies the higher losses level in this season.

On the other hand, Fig. 7 shows the relative power network losses normalized to the MV network demand (Relative Power Network Losses 1 index $-R P N L_{l}$ in (3)). In this case lower losses can be noticed during winter. Indeed, the copper losses due to cables and transformers increase whilst the iron losses in transformers slightly decrease due to the lower voltage level across the MV network. Consequently, the increase in demand during winter is not followed by the same increase in the aggregated power losses.

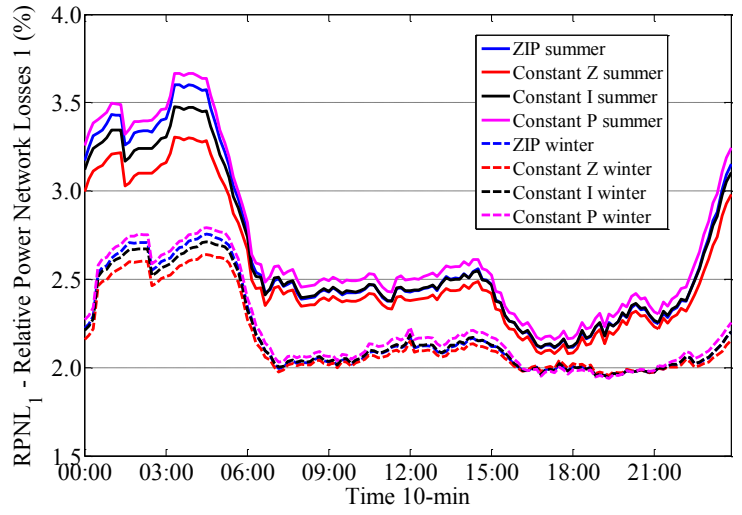

Fig. 7 Relative network power losses normalized to the total demand in summer and winter days

$$
R P N L_{1}=\frac{A P N L}{\text { Demand }_{M V}} \cdot 100
$$

This explains why the relative network losses are higher in summer than in winter, Fig. 7. This is particularly true during night when the share of iron losses in the aggregated is higher.

In Fig. 8 the power network losses estimated with every load model $(A P N L)$ are normalized to those obtained with the time-varying ZIP model $\left(A P N L_{Z I P}\right)$ here adopted as benchmark producing the Relative Power Network Losses 2 index, $\left(R P N L_{2}\right)$ in (4).

$$
R P N L_{2}=\frac{A P N L}{A P N L_{\text {ZIP }}} \cdot 100
$$

The results highlight that the constant power load model (Constant $\mathrm{P}$ in Fig. 8) underestimates the power network losses in both seasons compared to the other classic models.

This is due to the relatively high LV busbar voltage (above $240 \mathrm{~V}$ i.e., $1.04 \mathrm{pu}$ ) typically found in UK distribution networks [16] as shown in Fig. 9 for an example. The nominal $\mathrm{LV}$ transformer ratio $(11 / 0.433 \mathrm{kV})$ that provides a boost of $8.12 \%$ compared to the nominal voltage $\mathrm{V}_{0}$ justifies this outcome. Consequently, this leads to higher demand (as $V>V_{0}$ implies a $P>P_{0}$ in (1)) and thus to higher network losses. The analysis of a real MV network allowed capturing this feature.

The constant impedance load models overestimates up to $5 \%$, in both seasons, the power network losses providing the worst performance among the three classic load models. The quadratic relationship with the voltage justifies this outcome.

The constant current load model (Constant I in Fig. 8) showed the best performance in winter with a maximum error in the power losses quantification of $2.5 \%$ in morning hours. On the other hand, it was slightly outperformed by the constant power load model during summer due to the lower responsiveness of the demand as previously explained.

It is worth highlighting that the reduced penetration of resistance-based appliances in summer made the overall demand less responsive to voltage variations (i.e., a lower $n p$ ). 


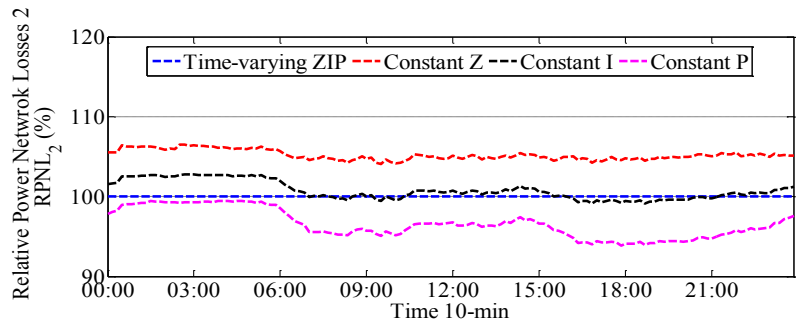

a)

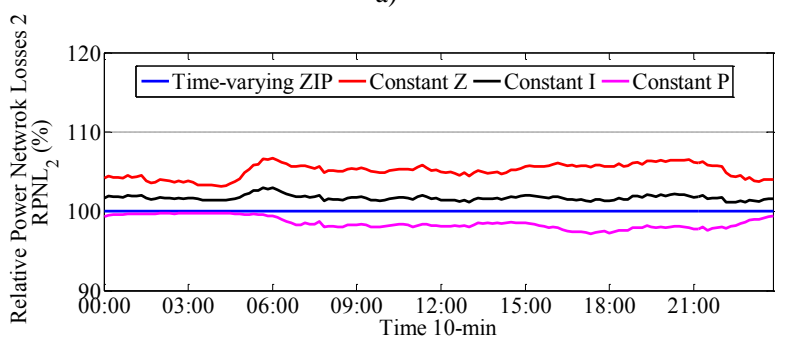

b)

Fig. 8 Network power losses normalized to the ZIP model ones in: a) winter day b) summer day

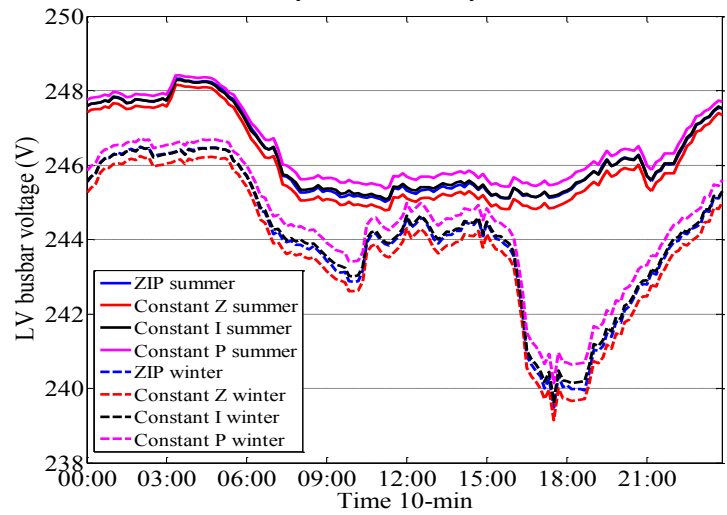

Fig. $9 \mathrm{LV}$ busbar voltage profile for the most remote secondary substation in summer and winter days

This phenomenon is captured by the time-varying load model as highlighted in Fig. 10 where a reduction of the $n p$ parameter can be noticed throughout the day. This explains the seasonal variation in the losses quantification accuracy of the classic load models.

Table IV shows the energy losses per load model $(E L)$ as well as their relative variation $\left(\Delta_{E L}\right)$ to the ZIP losses $\left(E L_{Z I P}\right)$ here adopted as benchmark (5).

$$
\Delta_{E L}=\frac{E L-E L_{Z I P}}{E L_{Z I P}} 100
$$

Similar trends found for the power losses can be noticed in term of energy. In particular, in winter the traditional constant power load model (Constant P) underestimates the energy losses of around $2.96 \%$ compared to the time-varying ZIP whilst in summer outperforms the other models with only a $1.53 \%$ error. An error of $5 \%$ is noticed with the constant impedance (Constant Z) load model in both summer and winter season.

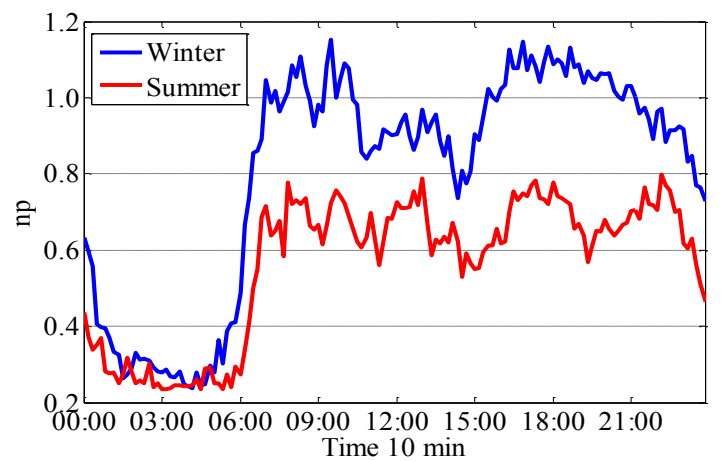

Fig. 10 Aggregated time-varying ZIP load model at primary substation in summer and winter days

TABLE IV ENERGY LOSSES

\begin{tabular}{|c|c|c|c|c|}
\hline \multirow[b]{2}{*}{ Load Model } & \multicolumn{2}{|c|}{ Winter } & \multicolumn{2}{|c|}{ Summer } \\
\hline & $\begin{array}{c}\text { Energy } \\
\text { Losses } \\
\text { EL } \\
\text { (MWh) }\end{array}$ & $\begin{array}{c}\text { Energy } \\
\text { Losses } \\
\text { Variation } \\
\Delta_{\mathrm{EL}}(\%) \\
\end{array}$ & $\begin{array}{c}\text { Energy } \\
\text { Losses } \\
\text { EL } \\
\text { (MWh) }\end{array}$ & $\begin{array}{c}\text { Energy } \\
\text { Losses } \\
\text { Variation } \\
\Delta_{\mathrm{EL}}(\%)\end{array}$ \\
\hline ZIP (reference) & 5.141 & 0 & 3.846 & 0 \\
\hline Constant $\mathrm{P}$ & 4.989 & -2.96 & 3.787 & -1.53 \\
\hline Constant I & 5.171 & +0.06 & 3.991 & +3.77 \\
\hline Constant Z & 5.404 & +5.11 & 4.045 & +5.17 \\
\hline
\end{tabular}

Although the constant current (Constant I) load model during winter introduced an error in the power losses estimation up to $2.5 \%$ (Fig. 8-a, black dashed line at night) in term of energy only an error as small as $0.06 \%$ was found when compared to the ZIP, Table IV.

This can be also deduced from Fig. 8-a where, except for few hours at night, the power losses estimated with this model are almost coincident with the ZIP ones. However, during summer $3.77 \%$ error in energy losses was found, Table IV.

Consequently, to quantify both power and energy losses during winter the constant current load model (if no timevarying load models are available) should be adopted. On the other hand, the constant power load model should be preferred for the quantification during summer. Indeed, no single classic load model shows the best performance for both seasons. This in turn highlights the limitations of simple load models where the time-varying nature of the demand composition is neglected.

Moreover, it was found that the load model do not have a significant impact on the voltage profiles as shown in Fig. 9 for an example. Therefore, those operational and/or planning strategy studies where management of voltages is investigated can use any load model as its influence on the final results will be negligible.

\section{CONCLUSIONS}

The impact that load models have on the quantification of power and energy network losses on a real UK $11 \mathrm{kV}$ network was explored in this work. In particular, the three classic load models, i.e., constant current, constant power and constant impedance were compared with a time-varying ZIP load model specifically developed for the UK residential demand. For this purpose, a 10-min resolution power flow analysis was carried out for both a summer and winter day considering realistic domestic profiles and available monitoring data. 
It was found that the constant power load model underestimates the network power losses, in both seasons, when compared to the remaining classic load models. This is mainly due to the relatively high LV busbar voltage (above $240 \mathrm{~V}$ i.e., $1.04 \mathrm{pu}$ ) typically found in UK networks. Similar figures have been obtained in terms of energy losses where the constant power load model leads to an underestimation ranging from 1.5 to around $3 \%$. Nonetheless, this model showed the best performance, compared to the remaining classic load models, during summer. Consequently, if no timevarying load models are available, the evaluation of network losses during summer, either power or energy, should consider the constant power load model.

On the other hand, during winter the constant current load model should be preferred as in this period it outperforms the other classic load models. Indeed, the higher responsiveness in voltage variation that characterizes the winter demand is better captured by this particular load model.

The constant impedance load model showed the worst performance and consequently should in general be avoided in any analysis in which the quantification of network losses is key.

The fact that no single classic model shows a good performance for both seasons highlights the limitations of simple time-constant load models.

In addition, no significant effects on voltage profiles were found with the different load models. Therefore, studies focusing on the management of voltages can adopt any load model without significantly impacting on the final outcomes.

\section{AKNOWELDGEMENTS}

This work has been funded by Electricity North West Limited (ENWL), UK, through the Ofgem's Low Carbon Networks Fund Tier 2 Project "Customer Load Active System Services", 2013-2015. The authors would like to thank the support of ENWL for the funding and making available the network-related data.

\section{REFERENCES}

[1] L. F. Ochoa and G. P. Harrison, "Minimizing energy losses: Optimal accommodation and smart operation of renewable distributed generation," IEEE Trans. on Power Systems, vol. 26, pp. 198-205, Feb. 2011.

[2] K. Clement-Nyns, E. Haesen, and J. Driesen, "The Impact of Charging Plug-In Hybrid Electric Vehicles on a Residential Distribution Grid," Power Systems, IEEE Transactions on, vol. 25, pp. 371-380, 2010.

[3] V. H. Mendez, J. Rivier, and T. Gomez, "Assessment of energy distribution losses for increasing penetration of distributed generation," IEEE Trans. on Power Systems, vol. 21, pp. 533-540, May 2006.
[4] A. Chauhan and S. Rajvanshi, "Non-Technical Losses in power system: A review," in Power, Energy and Control (ICPEC), 2013 International Conference on, 2013, pp. 558-561.

[5] M. Diaz-Aguilo, J. Sandraz, R. Macwan, F. de Leon, D. Czarkowski, C. Comack, et al., "Field-Validated Load Model for the Analysis of CVR in Distribution Secondary Networks: Energy Conservation," Power Delivery, IEEE Transactions on, vol. 28, pp. 2428-2436, 2013.

[6] W. Zhaoyu and W. Jianhui, "Time-Varying Stochastic Assessment of Conservation Voltage Reduction Based on Load Modeling," Power Systems, IEEE Transactions on, vol. 29, pp. 2321-2328, 2014.

[7] A. Rossoni, R. de F V Dresch, A. S. Bretas, A. L. Bettiol, A. Carniato, L. F. N. Passos, et al., "Load models effects on distribution system losses estimation: A numerical study," in Power and Energy Society General Meeting (PES), 2013 IEEE, 2013, pp. 1-5.

[8] D. Singh, R. K. Misra, and D. Singh, "Effect of load models in distributed generation planning," IEEE Trans. on Power Systems, vol. 22, pp. 2204-2212, Nov. 2007.

[9] A. Ballanti and L. F. Ochoa, "Initial assessment of voltage-led demand response from UK residential loads," in IEEE/PES Conference on Innovative Smart Grid Technologies, Washington, 2015, p. 5.

[10] R. C. Dugan and T. E. McDermott, "An open source platform for collaborating on smart grid research," in Power and Energy Society General Meeting, 2011 IEEE, 2011, pp. 1-7.

[11] I. Richardson, M. Thomson, D. Infield, and C. Clifford, "Domestic electricity use: A high-resolution energy demand model," Energy and Buildings, vol. 42, pp. 1878-1887, Oct. 2010.

[12] CIGRÉ, Modelling and Aggregation of Loads in Flexible Power Networks: CIGRÉ, 2014.

[13] J. V. Milanović, "On unreliability of exponential load models," Electric Power Systems Research, vol. 49, pp. 1-9, 2/15/ 1999.

[14] A. Bokhari, A. Alkan, R. Dogan, M. Diaz-Aguilo, F. de Leon, D. Czarkowski, et al., "Experimental determination of the ZIP coefficients for modern residential, commercial, and industrial loads," IEEE Trans. on Power Delivery, vol. 29, pp. 1372-1381, Jun. 2014.

[15] "Families and Households, 2013," 2014.

[16] C. Zhao, "Understanding LV Network Voltage Distribution - UK Smart Grid Demonstation Experience," presented at the IEEE ISGT America, Washington DC, 2015.

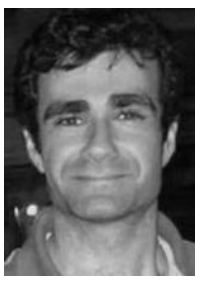

\section{BIOGRAPHIES}

Andrea Ballanti received the B.Eng and the M.Sc degree from the University of Cagliari, Italy in 2010 and 2013 respectively. $\mathrm{He}$ is currently a $\mathrm{PhD}$ candidate at the University of Manchester, UK. He is involved with a UK distribution network operator in the "Customer Load Active System Services" (CLASS) project. His current research interests include voltage driven demand response, load modelling and MV-LV network modelling

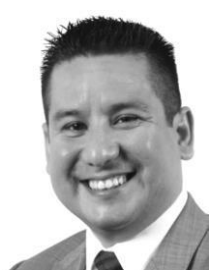

Luis F. Ochoa (S'01, M'07, SM'12) received the B.Eng. degree from UNI, Lima, Peru, in 2000 and the M.Sc. and Ph.D. degrees from UNESP, Ilha Solteira, Brazil, in 2003 and 2006, respectively. He is a Senior Lecturer in Smart Distribution Networks at The University of Manchester, UK. His current research interests include network integration of distributed energy resources and future low-carbon distribution networks. 